Monatsschrift f. Geburtshülfe u. Gynäkologie 1935;99:379-380

\title{
In memoriam Hofrat Prof. Dr. Emil Knauer
}

Vorstand der Universitätsfrauenklinik in Graz

Am 14. Mai dieses Jahres ist Emil Knauer in Graz einer schleichen-den Thrombose erlegen. Ein Leben erfüllt von Pílichttreue und größter Gewissenhaftigkeit hat seinen Abschluß gefunden. Am 27. Februar 1867 in Preßburg geboren, besuehte Knauer das dortige Gymnasium. Seine ärztliche und wissenschaftliche Ausbildung

genoß er in Wien zu einer Zeit. da eine Reihe glanzvoller Namen die Wiener Schule weit über die Grenzen des deutschen Sprachgebietes hinaus berühmt machte. Als junger Arzt konnte Knauer in der medi-zinischen Klinik Xoíhnagels und später als Operationszögling bei Billrolh tätig sein. Dann kam Knauer zu Chrobak, der den immer pflicht-bewußten. vorsichtigen und ernsten Mitarbeiter bald besonders schätzen lernte und zu seinem Assistenten wählte. Knauer ist ganz in den Geist dieses gediegenen Altmeisters der Geburtshilfe und Gy äkologie eingedrungen, und so konnte sein Lehrer den jungen Dozenten nach Rosthorns Berufung von Graz nach Heidelberg der Grazer Fakultät als ebenbürtigen Nachfolger empfehlen. Im Jahre 1903 erfolgte seine Berufung. Bis zu seinem Tode blieb die Grazer Universitätsfrauenklinik sein liebgewordenes Arbeitsfeld. das er trotz ehrenvoller Berufungen nicht verlassen hat. Im Jahre 1912 wurde nach K $\cap$ auers Plänen an Stelle

380 In memoriam Hofrat Prof. Dr. Emil Knauer. - Personalien.

der bis dahin unzulänglichen Räume ein Neubau errichtet, der die Grazer Klinik zu einer der schönsten Osterreichs macht.

In Graz hat sich Knauer die Liebe und das Vertrauen weitester Kreise erworben. Nicht nur aus der Stadt und Umgebung, auch aus dem angrenzenden Jugoslawien und deni Balkan kam eine große Menge von Kranken, und so wurde die Grazer Klinik eine Heilstätte für viele, weit über Osterreichs Grenzen hinaus. Ihr starker Belag, ihre vortreff-lichen neuzeitlichen Einrichtungen machten sie auch zu einer vielbe-suchten Lehrstätte, deren vortreffliche Leitung und ruhige zielbewußte Führung allgemeine Anerkennung fand.

Knauer war ein strenger Lehrer; ehrenvoll wares, beiihmbestanden zu haben. Viele waren ihm später für die einstige Strenge dankbar, die zur Erwerbung eines reichen und gediegenen Wissens zwang.

Persönlich bescheiden und zurückhaltend, war Knauer als Wissen-schaftler ein Feind jeder nichtssagenden Vielschreiberei. Seine Arbeiten sind von größter Gewissenhaftigkeit, so daß das, was er schrieb, als unumstößlich gelten konnte. Noch bis in die letzten Jahre war er durch die Abfassung von Beiträgen für Lehr- und Handbücher tätig, und die von ihm stammenden Abschnitte sind durch beispielgebende Genauig-keit und Gediegenheit ausgezeichnet. Als Geburtshelfer ist Knauer immer dem Grundsatz der Chrobak-schen Schule, ,, den Naturkräften weitgehend zu vertrauen", treu ge-blieben. War aber ein operativer Eingriff geboten, so geschah er in überlegen einfacher, ruhiger Art. Das gleiche gilt von seiner Tätigkeit als Gynäkologe. Obwohl Meister der operativen Technik, entschloß er sich nur dann zu einem Eingriff, wenn dieser allein Hilfe versprach. 
Jeder neu auftauchenden Heilmethode setzte er gesunde Kritik entgegen. Hatte sich jedoch etwas gut bewährt, so tat er alles, um es sofort in Anwendung zu bringen. So hat Knauer nach Bekanntwerden der ersten Erfolge der Strahlenbehandlung aus eigenen Mitteln Radium beschafft, das der Klinik zur Verfügung stand, und ein mit modernsten Mitteln ausgestattetes Institut für Strahlentherapie an der Klinik war sein Werk.

Uns, seinen engeren Schülern gegenüber, war der Meister ein warm-fühlender, stets hilfsbereiter Freund, der immer, wenn wir uns an ihn wandten, gern aus seiner reichen Erfahrung mitteilte. In Knauer vei lieren die Kranken einen edlen, mitfühlenden und immer hilfsbereiten Arzt, die Wissenschaft einen gewissenhaften, kritischen und erfolgreichen Forscher, die Studenten einen tüchtigen Lehrer. Wir Schüler trauern um den unermüdlichen, stets verläßlichen Ratgeber in alien Belangen unseres verantwortungsvollen Berufes.

$11 \mathrm{cms}$ Zacherl (Innsbruck).

Personalien.

Der Oberarzt der $\Gamma$ Jniversitäts-Frauenklinik, Prof. Dr. Fr. Chr. Getter in Breslau, wurde zum Primärarzt an der geburtshilfПch-gynäkologischen Abteilung des Allerheiligen-Hospitals ernannt.

Privatdozent Dr. Rudolf Hubert in Greifswald ist zum nicht beamteten a. o. Professor ernannt.

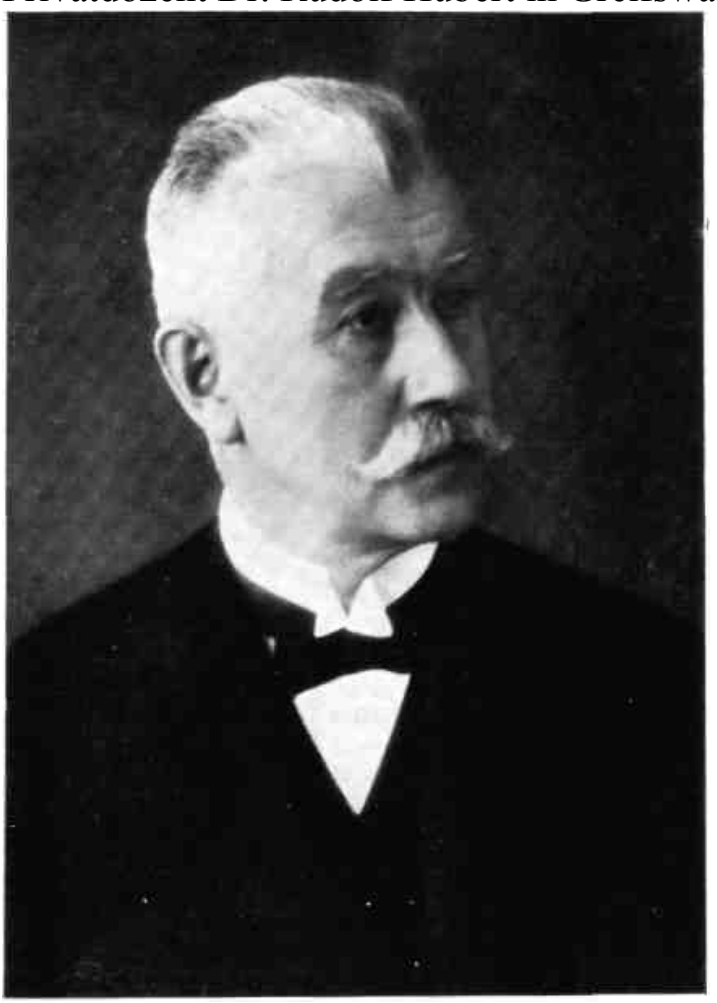

